\title{
On the incorporation of protic ionic liquids imbibed in large pore zeolites to polybenzimidazole membranes for high temperature PEMFCs
}

\author{
A. Eguizábal ${ }^{1}$, J. Lemus ${ }^{1}$, M.P. Pina ${ }^{1,2}$ \\ ${ }^{1}$ Chemical Engineering Department, Nanoscience Institute of Aragón (INA); Edif. I+D, Campus \\ Rio Ebro, c/Mariano Esquillor s/n, 50018 Zaragoza, Spain \\ ${ }^{2}$ Networking Research Center on Bioengineering, Biomaterials and Nanomedicine, CIBER- \\ $B B N, 50018$ Zaragoza, Spain \\ Corresponding Author: tel.+34 976 761155, fax. +34 976762142 e-mail: mapina@unizar.es
}

\section{Abstract}

Conducting fillers based on 2-hydromethyl) trimethylammoniun dimethyl phosphate (IL1), N,N-dimethyl-N-(2-hydroxyethyl) ammonium bis(trifluoromethanesulfonyl)imide (IL2) and 1-H-3-methylimidazolium bis(trifluoromethanesulfonyl)imide (IL3) encapsulated in large pore zeolites $\left(\mathrm{NH}_{4} \mathrm{BEA}\right.$ and $\mathrm{NaY}$ ) have been added to the PBI casting solution for the preparation of high temperature proton exchange membranes (HTPEMs). The filler loading has been systematically varied from $3 \%$ to $20 \%$ wt. for all the studied composites. The morphological, physicochemical, and electrochemical properties of the as prepared hybrid doped PBI membranes have been fully characterized. For a given conduction filler, the optimum loading is found to be $3 \%$ wt. as inferred from the conductivity measurements at 0.05 water molar fraction. Among the tested, the outstanding electrolyte membranes are those containing IL3-NaY. The exhibited through-plane proton conductivity is $54 \mathrm{mS} \cdot \mathrm{cm}^{-1}$ at $200{ }^{\circ} \mathrm{C}$ for the optimum PBI+IL3-NaY_3\%wt hybrid membrane. The so obtained results are explained by the assisted 1- $\mathrm{H}-3-$ methylimidazolium and bis(trifluoromethanesulfonyl)imide hydrogen bonding type interactions, clearly beneficial for the proton conduction processes. Moreover, the $\mathrm{H}_{2}$ permeability values for the hybrid electrolyte membranes and pure PBI are quite similar at the examined conditions; indicating the suitability of the preparation procedure in 
terms of fuel cross-over. The $\mathrm{H}^{+} / \mathrm{H}_{2}$ transport selectivity of the optimum IL3-NaY composite membrane clearly outperforms pure PBI and zeolite-PBI counterparts at $50^{\circ}$, $100^{\circ}$ and $150{ }^{\circ} \mathrm{C}$. Finally, the optimum composite membranes have been validated in $\mathrm{H}_{2} / \mathrm{O}_{2}$ single cell under non humidified conditions up to $180{ }^{\circ} \mathrm{C}$ as a "proof of concept" demonstration.

Keywords: ionic liquids; large pore zeolites; hybrid polybenzimidazole membranes; assisted proton transport; high temperature applications; $\mathrm{H}_{2} / \mathrm{O}_{2}$ single cell performance.

\section{Introduction}

It is expected that fuel cell systems play a key role and contribute, in a more effective way, to satisfy energy market demands by $2050^{1}$. Long-term and breakthrough orientated research is progressively focused on degradation and lifetime fundamentals related to materials and typical operation environments for all power ranges. In particular, the availability of commercial membrane materials having high proton conductivity almost unaffected by temperature and relative humidity is identified as one of the main bottlenecks preventing the commercialization of FC technologies. The higher operation temperatures in the PEMFC could be accompanied with higher CO tolerance, better reaction kinetics, and simpler water management.

Commercially available polybenzimidazole (PBI) has been the most extensively studied and used in membranes doped with all sorts of strong inorganic acids for high temperature applications up to $200^{\circ} \mathrm{C}^{2}$. By far, the most common approach is phosphoric acid impregnated systems. However, phosphoric acid autodehydration at temperatures above $140^{\circ} \mathrm{C}$ is a serious limitation due to the formation of lower conductivity oligomers like pyrophosphoric acid. On the other hand, elution of the 
water soluble phosphoric acid from the membrane and dilution of the acid in the membrane can occur when the vapor produced at the cathode in the operation process of fuel cells is not eliminated. Among the main strategies to improve the performance and stability of current PBI membranes, the most studied are: i) ionic cross-linking of polymeric acids and polymeric bases; ii) use of covalently cross-linked acids or halides; iii) composite organic-inorganic membranes from PBI and inorganic fillers. Accordingly, a new generation of advanced PBI membranes are currently commercially available (i.e. Celtec ${ }^{\circledR}-\mathrm{P} 1000$ MEA from BASF $^{3}$ and fumapem ${ }^{\circledR}$ from FuMA-Tech ${ }^{4}$ ).

In general, the use of composite materials is a clear research path for the development of improved electrolyte membrane materials for high temperature applications. Thus, the inclusion of different inorganic fillers ${ }^{5,6,7,8,9}$ to the casting PBI solution (zirconium phosphates, phosphotungstenic acid, silico-tungstenic acid, zirconium tricarboxilphosphate, polyoxometals, sulfonic silica nanoparticles, titanium oxide) has been already proposed to enhance the conduction performance and fuel cross-over properties of PBI membranes at temperatures above $120^{\circ} \mathrm{C}$. In general, the as prepared composite membranes show higher water uptake, acid doping levels and improved mechanical properties comparing to pristine PBI counterparts. In an attempt to improve interactions at the interface, external surface functionalization of either inorganic $^{10,11}$ or organic ${ }^{12,13}$ fillers has also been attempted. In particular, novel dense and porous hybrid PBI membranes ${ }^{14}$ including microporous ETS-10 titanosilicate type materials have been previously developed by our group for high temperature PEMFC applications. Some of these authors attribute the enhanced performance of composite membranes to the formation of new proton conducting networks that formed along the functionalized filler's surface ${ }^{12,13,14}$. 
On the other hand, the deployment of ionic liquids (ILs) as proton transport carriers in the polymer membrane is emerging as an attractive alternative to overcome the operational limitations above $100^{\circ} \mathrm{C}$. These organic salts are able to transport protons due to their acid-base character and their capability to form complex or intermolecular hydrogen bonds ${ }^{15}$. The main challenge hindering the use of ionic liquids as proton conductor in PEMFCs is the phase separation process that takes place between the polymer phase and ionic liquids resulting in inhomogeneous membranes. Nevertheless, conducting polybenzimidazole based systems containing ILs has been already reported by dissolving the polymer and IL in a common solvent and casting the film ${ }^{16,17,18}$. The pioneer work of Greenbaum et al., ${ }^{16}$ demonstrated the feasibility of anhydrous proton solvent $\mathrm{H}_{3} \mathrm{PO}_{4}$, the protic ionic liquid 1-propyl-3-methylimidazolium dihydrogen phosphate and $\mathrm{PBI}$ for operation up to $150^{\circ} \mathrm{C}$. Under completely anhydrous conditions, these novel membranes exhibited conductivities up to $2.04 \mathrm{mS} \cdot \mathrm{cm}^{-1}$ at $150^{\circ} \mathrm{C}$. In fact, the incorporation of ionic liquid into $\mathrm{H}_{3} \mathrm{PO}_{4} / \mathrm{PBI}$ complex significantly increased the ionic conductivity of the membranes. In a step further, Hsu et al., ${ }^{18}$ prepared composite membranes from a fluorine-containing PBI with 1-hexyl-3-methylimidazolium trifluoromethanesulfonate. The ionic liquid based composite membranes shown a significant improvement in thermal stability compared to the $\mathrm{H}_{3} \mathrm{PO}_{4} / \mathrm{PBI}$ system and ionic conductivities up to $16 \mathrm{mS} \cdot \mathrm{cm}^{-1}$ at $250^{\circ} \mathrm{C}$ under anhydrous conditions.

In contrast to published works dealing with PBI-ILs membranes, the electrolyte membrane concept proposed in our previous work $^{19}$ was based on the simplest Supported Ionic Liquid Membrane approach commonly used for Gas Separations. Thus, randomly porous doped PBI membranes (80\% in porosity) containing 1-H-3methylimidazolium bis(trifluoromethanesulfonyl)imide (IL3) were tested for high temperature PEMFCs. Through plane conductivity values above $35 \mathrm{~ms} \cdot \mathrm{cm}^{-1}$ were 
reported at $160^{\circ} \mathrm{C}$ in presence of $0.05 \mathrm{H}_{2} \mathrm{O}$ molar fraction. In order to avoid the IL leakage/dragging with time on stream by water reaction molecules, microporous ETS10 titanosilicate coatings were performed over supported protic ionic liquid membranes. The so obtained microporous layers also reduce fuel cross-over at the expense of higher ohmic polarization.

Unlike previously, the strategy herein proposed to alleviate IL dragging phenomena with time on stream is the IL immobilization in large pore zeolites, which are further deployed as fillers to the PBI casting solution. The encapsulation procedures for different ammonium based protic ionic liquids within the microporous framework of FAU and BEA zeolites have been recently studied ${ }^{20}$ in our group to improve the proton conductivity of the filler itself. In general, all the composites exhibited the same conductivity behaviour under anhydrous conditions: a gradual increase up to a maximum followed by a conductivity decay. This experimental observation was attributed to the weakly bounded water molecules desorption capable to ionic liquid dragging, and the maximum position was related to the hydrophilicity not only of the zeolitic host but also on the ionic liquid itself. Accounting from these results, the aim of this work is the preparation of hybrid doped PBI membranes based on conducting ILzeolite fillers with enhanced performance for high temperature PEMFCs applications. Firstly, the influence of the type and amount of composite filler over the phosphoric acid, water uptake and conductivity values of the as prepared membranes has been systematically analyzed to identify the best combination. Special attention to the membrane casting and doping steps has been carried out to check the potential ionic liquid dragging from the internal microporous surface. Once the outperforming membrane is defined, the second part of this work has been devoted to the characterization of the optimum electrolyte membrane and MEA testing in $\mathrm{H}_{2} / \mathrm{O}_{2}$ single 
cell at temperatures up to $180{ }^{\circ} \mathrm{C}$. The $\mathrm{H}_{2}$ permeability and $\mathrm{H}^{+} / \mathrm{H}_{2}$ transport selectivity values have been evaluated and compared with those values exhibited by pure PBI and bare zeolite-PBI counterparts at $50^{\circ}, 100^{\circ}$ and $150{ }^{\circ} \mathrm{C}$.

\section{Experimental}

\subsection{Starting Materials}

Two types of commercial large pore zeolites were used as ionic liquid hosts: $\mathrm{NH}_{4}$ BETA (denoted as BEA) supplied by Zeolyst International $(\mathrm{Si} / \mathrm{Al}$ ratio $=12.5)$ and $\mathrm{Na}$ type zeolite $\mathrm{Y}$ (denoted as $\mathrm{NaY}$ ) from Sigma Aldrich $(\mathrm{Si} / \mathrm{Al}$ ratio= 1.5). As guest molecules, ionic liquids based on ammonia and imidazolium salts were studied: (2hydroxymethyl) trimethylammonium dimethyl phosphate (denoted as IL1) purchased from Solvent Innovation, N,N-dimethyl-N-(2-hydroxyethyl) ammonium bis(trifluoromethanesulfonyl) imide (denoted as IL2), and 1-H-3-methylimidazolium bis(trifluoromethanesulfonyl)imide (denoted as IL3); both supplied by Solvionic ${ }^{21}$. Following the encapsulation procedures already described in previous works ${ }^{20,22}$, four different conducting fillers were prepared. Sohxlet extraction to remove the IL excess from the external microporous surface at solvent reflux temperature was performed in all the cases. The main properties of the as prepared composites, including conductivity values at $100^{\circ} \mathrm{C}$ as a function of relative humidity, are depicted in Table 1 . For the same preparation method and a BEA type zeolite, the IL1 loadings are always higher than IL2 counterparts (29\% wt. vs. 5\% wt.), in agreement with the lower molecular size of dimethyl phosphate anion. On the other hand, IL2 and IL3 loadings onto NaY zeolites are quite similar (17\% wt. vs. $19 \%$ wt.), due to both contains the same voluminous bis(trifluoromethanesulfonyl)imide anion. In addition, the zeolite framework seems to have a relevant influence on IL2 encapsulation, i.e. 17\% wt for NaY vs. 5\% wt for BEA 
composites. In the later case, issues related to the larger size of IL2 might result in lower loadings in BEA due to steric and diffusional factors.

Poly[2,2-(m-phenylene)-5,5-bibenzimidazole] (PBI) powder of high molecular weight purchased to FuMA-Tech (Fumion APH) has been dissolved in an autoclave under autogenous pressure at $240{ }^{\circ} \mathrm{C}$ for $24 \mathrm{~h} .0 .5 \mathrm{~g}$ of PBI powder, $0.01 \mathrm{~g}$ of $\mathrm{LiCl}$, as stabilizer, and $9.3 \mathrm{~g}$ of $\mathrm{N}-\mathrm{N}$ dimethylacetamide (DMAc) are mixed in the autoclave to obtain a PBI solution of $5 \%$ wt. in DMAc. Before use, the PBI solution is filtered to remove insoluble solids from the starting PBI powder.

\subsection{Membrane casting and phosphoric acid doping}

For the preparation of hybrid PBI membranes, the IL-zeolite composite is firstly evacuated in an oven at $120{ }^{\circ} \mathrm{C}$ for at least $24 \mathrm{~h}$. Afterwards, adequate amount of the conducting filler (from 3\% up to $20 \%$ wt. referred to the polymer) is mixed with the PBI-DMAc solution. The resulting solution is kept under sonication for $1 \mathrm{~h}$ to obtain a homogeneous mixture, whereas mechanical stirring is maintained (for at least $24 \mathrm{~h}$ ) until the casting process. The composite mixture is poured onto a glass plate $14 \mathrm{~cm}$ in diameter preheated to $60^{\circ} \mathrm{C}$, in an electrical oven without convection. A heating rate of $10^{\circ} \mathrm{C} / \mathrm{h}$ is kept up to $90^{\circ} \mathrm{C}$ and the membrane is maintained at this temperature for 12 hours to ensure the solvent evaporation. The dried membranes are peeled off by addition of DDW. Then, LiCl stabilizer is removed by successive membrane immersion cycles into boiling water during 2 h. A series of free-standing, homogeneous, translucent brown membranes (see Figure 1) with controlled thickness around $50 \mu \mathrm{m}$ has been

obtained (see Figure 2). The residual solvent (DMAc) is finally removed by evacuation (2 mbar) at $80^{\circ} \mathrm{C}$ during 24 hours. Following a similar procedure, pure PBI and bare zeolite-PBI membranes have also been prepared for comparison purposes. 
Finally, the PBI based membranes have been doped with $\mathrm{H}_{3} \mathrm{PO}_{4}$ by immersion in 11 $\mathrm{M}$ acid solutions at $80^{\circ} \mathrm{C}$ under stirring for 24 hours ${ }^{23}$. Afterwards, the samples are dried with blotting paper and finally evacuated (50 mbar) at $80^{\circ} \mathrm{C}$ for at least $24 \mathrm{~h}$. The phosphoric acid doping levels here reported have been calculated by weight difference between doped membrane " $\mathrm{m}_{\text {doped }}$ " (before wiping off the phosphoric acid excess) and without doping " $\mathrm{m}_{\mathrm{o}}$ " (after the $\mathrm{LiCl}$ removal), according to the following equation:

Doping level $(D . L)=\frac{\left(m_{\text {doped }}-m_{0}\right)}{m_{0}} \cdot \frac{M_{W}(P B I)}{M_{W}\left(H_{3} P_{4}\right)}$

\subsection{Characterization Techniques}

Thermogravimetric analyses (TGA) from room temperature up to $900^{\circ} \mathrm{C}$ under $\mathrm{N}_{2}$ flow and using $1^{\circ} \mathrm{C} / \mathrm{min}$ as heating rate have been carried out to quantify water and phosphoric acid uptake values. Thus, the evaluated composition of the doped PBI membranes developed in this work is compiled in Table 2. As it can be observed, hybrid membranes prepared from bare zeolite fillers have been also studied to assess about the benefits of IL embedding.

Morphology, thickness and homogeneity of the as prepared membranes have been studied by SEM (Inspect ${ }^{\mathrm{TM}}$ F50). ATR-FTIR analyses (VERTEX 70 equipment with microscope slide MKII Golden Gate ATR from 4000 to $600 \mathrm{~cm}^{-1}, 256$ scans and resolution of $0.05 \mathrm{~cm}^{-1}$ ) were performed to investigate the absorption peaks of the ionic liquids, zeolites and PBI backbone.

Proton conductivity was determined using the complex impedance method in a closed cell. Basically, through-plane conductivity measurements under $100 \mathrm{~cm}^{3} \mathrm{~N}_{2}$ $\mathrm{STP} / \mathrm{min}$ has been evaluated up to $200^{\circ} \mathrm{C}$ using $0.5^{\circ} \mathrm{C} / \mathrm{min}$ as heating rate. Considering water is the unavoidable by-product of PEM fuel cell reaction, all the conductivity tests 
were carried out in presence of 0.05 water molar fraction. The phosphoric acid doped membranes were previously conditioned for at least $24 \mathrm{~h}$ in a vacuum oven at $80{ }^{\circ} \mathrm{C}$.

$\mathrm{H}_{2}$ permeability measurements were performed in the permeation cell described in our previous work ${ }^{14}$. The flow rates of the feed $\left(10 \mathrm{~cm}^{3} \mathrm{H}_{2} \mathrm{STP} / \mathrm{min}\right)$ and sweep (10 $\mathrm{cm}^{3} \mathrm{Ar} \mathrm{STP} / \mathrm{min}$ ) streams were controlled by means of mass flow controllers. The permeate gas analysis composition was analyzed by an on-line gas chromatograph (Agilent 3000 MicroGC).

\subsection{MEA assembly and $\mathrm{H}_{2} / \mathrm{O}_{2}$ single cell testing}

Catalyst coated substrate (CCS) electrodes were prepared from commercial Freundenberg H2315 CX165 carbon paper suitable for High Temperature Applications. The optimum electrolyte membrane $\left(2.9 \times 2.9 \mathrm{~cm}^{2}\right)$ was sandwiched between the homemade electrodes with $0.5 \mathrm{mg} \mathrm{Pt} \mathrm{cm}^{2}$ in anode and cathode respectively. MEA assembly was carried out by pressing at $120^{\circ} \mathrm{C}$ and 4 bar during $30 \mathrm{~min}$. Pressing time was increased up to $4 \mathrm{~h}$ for hybrid PBI membranes due to their poorer plastic behavior. 25-micron thick Kapton sub-gaskets and 215 -micron thick Silicone gaskets were used to improve FC performance. Finally, stainless steel bipolar plates squared in shape (2.5 $\mathrm{x} 2.5 \mathrm{~cm}^{2}$ as total area and $2 \times 2 \mathrm{~cm}^{2}$ as effective area) were used ${ }^{24}$ for single cell assembly. The configuration channel flow is serpentine geometry with two channels in parallel.

$\mathrm{H}_{2} / \mathrm{O}_{2}$ single cell performance was evaluated in a pilot plant described elsewhere ${ }^{25}$. The single cell was inserted in an oven where the temperature was controlled with a thermocouple in contact with the bipolar plate. In particular, the procedure to acquire polarization curves was the following. For a given temperature $\left(120^{\circ}-150^{\circ}-180^{\circ} \mathrm{C}\right)$, the cell was firstly fed with pure nitrogen on both sides at a rate of $0.15 \mathrm{~cm} 3 \mathrm{STP} / \mathrm{min}$ and 
kept overnight. After temperature stabilization, nitrogen feed was switched to oxygen and hydrogen to cathode and anode respectively; and current density response to various cell voltage levels (ranging from $0.8 \mathrm{~V}$ to $0.1 \mathrm{~V}$ and vice versa) was monitored until steady state conditions. To simulate the load to the stack, a decade resistance box (IT8512 C supplied by Itech DC Electronics Load) with a minimum value of $0.01 \Omega$ has been used to force the stack to yield the maximum current intensity. In all the cases, the registered current density values were nearly 10 times lower than those reported for state of the art PBI membranes [19] due to further optimization on MEA assembly and reactants flow distribution, out of the scope of this work, is required.

\section{Results and Discussion}

\subsection{Filler loading effect onto PBI membranes}

According to the published literature, the incorporation of microporous conducting fillers to the PBI casting solution could led to: i) decrease the fuel-cross over due to molecular sieving properties of the inorganic loading and the improved organicinorganic interface owing to the presence of new functional groups prone to new type of interactions; and, ii) promote the ionic conductivity as a result of the higher water and phosphoric acid uptake values and the presence of new conduction pathways. Therefore, the ionic liquids have been chosen on the basis of PBI affinity towards ammonium (IL1 and IL2) and imidazole (IL3) based ionic liquids. In particular, it is expected the generation of an additional hydrogen bonding network able to improve proton conductivity at elevated temperatures. Moreover, the use of the same anion as $\mathrm{H}_{3} \mathrm{PO}_{4}$, i.e. dimethyl phosphate for IL1, could facilitate the proton carrier dispersion throughout the membrane thickness. 
Firstly, a parametric study on the IL-zeolite loading effect $(0 \%, 3 \%, 10 \%$ and $20 \%$ wt. referred to the polymer) onto phosphoric acid doping and proton conduction properties was carried out. To asses about the benefits imposed by the ionic liquids, pure PBI and bare zeolite-PBI membranes have been also prepared for comparison.

Figure 3 shows the conductivity measurements from room temperature up to $200^{\circ} \mathrm{C}$ as a function of the BEA type filler loading. The phosphoric acid uptake values, estimated by TGA, are always higher for the hybrid membranes (see Table 2 and Figure 4) in agreement with published literature ${ }^{5-9}$. In general, the exhibited "through-plane" conduction performance correlates well with the phosphoric acid solution uptake values for a given BEA type filler data set: 3\%wt. of loading $>20 \%$ wt. of loading $>10 \%$ wt. of loading $>0 \%$ wt. of loading.

In general, the proton conduction properties should be considered as a result of $\mathrm{H} 2 \mathrm{O}$, $\mathrm{H} 3 \mathrm{PO} 4, \mathrm{H} 2 \mathrm{P} 2 \mathrm{O} 7$ and ionic liquid molecules contribution to the proton conduction mechanism (see section 3.2.1 below). Such molecules content is clearly affected by the filler addition. As the filler loading increases, a dilution effect on basic PBI sites and subsequent lower phosphoric acid loadings occur. On the other hand, the overall hydrophilic properties of the membrane due to the zeolite addition and total phosphoric acid uptake values due to the interactions with ionic liquid ions leached out from the microporous cavities are also improved. Accounting from the homogeneous distribution of the commercial zeolite crystals 1-3 microns in size within the polymer matrix (see Figures 1 and 2), the expected intermolecular space among PBI chains (i.e. pore size) could be considered constant with zeolite/IL loading level. However, the fraction of voids (i.e. porosity) capable to play as water/phosphoric acid reservoirs will increase with filler addition. Thus, the lowest water and phosphoric acid contents, expressed as H2O/PBI+filler and H3PO4/PBI-filler, are always exhibited by hybrid membranes with 
$10 \%$ wt. of filler (see Table2). In fact, this membrane data set reveals as the less adequate in terms of conduction properties (see Figures 3 and 5).

Among the BEA based membranes at optimum loading, both composite fillers IL1BEA and IL2-BEA clearly outperform bare BEA-PBI. Moreover, PBI+IL1-BEA_3\% wt and PBI+IL2-BEA_3\% wt. show similar performance above $150^{\circ} \mathrm{C}$ in spite of the conductivity differences of the fillers themselves ${ }^{20}$ (i.e. $2 \mathrm{mS} \cdot \mathrm{cm}^{-1}$ vs. $0.2 \mathrm{mS} \cdot \mathrm{cm}^{-1}$ at $180^{\circ} \mathrm{C}$ for IL1-BEA and IL2-BEA respectively). At this point, it is worthwhile to remark that the less intrinsic proton conductivity of IL1 vs. IL2 (i.e. $50 \mathrm{mS} \cdot \mathrm{cm}^{-1}$ vs. 159 $\mathrm{mS} \cdot \mathrm{cm}^{-1}$ at $150^{\circ} \mathrm{C}$ ), is counterbalanced by the higher encapsulated amount in BEA host (i.e. $29 \%$ wt. vs. $5 \% w t)$.

The distinguished conductivity pattern at elevated temperatures depicted by membranes containing ILs imbibed fillers could be explained by a proton conduction mechanism where ionic liquid molecules dragged from the internal microporous surface of the zeolite fillers are certainly contributing to the H-bonding network. Accounting from the hydrophilic nature and water solubility properties of IL1 and IL2 ${ }^{20}$, their leaching is prone to occur during phosphoric acid doping at $80^{\circ} \mathrm{C}$ under stirring.

Comparing to the pristine PBI membrane, the relatively high proton conductivities of PBI+IL2-BEA_3\% wt. are noteworthy (i.e. $13 \mathrm{mS} \cdot \mathrm{cm}^{-1}$ vs. $3 \mathrm{mS} \cdot \mathrm{cm}^{-1}$ at $120^{\circ} \mathrm{C}$; and 25 $\mathrm{mS} \cdot \mathrm{cm}^{-1}$ vs. $9 \mathrm{mS} \cdot \mathrm{cm}^{-1}$ at $\left.200^{\circ} \mathrm{C}\right)$.

Similarly, Figure 5 shows the conductivity measurements from room temperature up to $200^{\circ} \mathrm{C}$ as a function of the $\mathrm{NaY}$ type filler loading. Once again, the phosphoric acid uptake values are always higher for the hybrid membranes (see Table 2 and Figure 6). Above all, it is quite noteworthy the composition of PBI+IL3-NaY_3\%wt., being the $\mathrm{H}_{3} \mathrm{PO}_{4} /(\mathrm{PBI}+$ filler) mass ratio almost one order of magnitude higher than pristine PBI and, no less than two folds for the others. SEM micrographs of such membrane data set 
are depicted in Figure 2 to illustrate the homogeneous distribution of the inorganic particles across the membrane thickness. The FTIR spectra for doped IL3-NaY composite membranes are shown in Figure 7. The pristine PBI film exhibited characteristic absorption bands at $1631 \mathrm{~cm}^{-1}$ due to the stretching vibrations of the $\mathrm{C}=\mathrm{N}$ groups. The asymmetric T-O-T stretching vibration (where $\mathrm{T}$ denotes $\mathrm{Si}$ or $\mathrm{Al}$ atoms) was observed at $1080 \mathrm{~cm}^{-1}$, and becomes more noticeable as the filler loading increases.

Unlike BEA counterparts, the exhibited conduction behaviour of hybrid membranes containing IL3-NaY is clearly outperforming, whatever the filler loading used; although the optimum is also identified at $3 \% \mathrm{wt}\left(54 \mathrm{mS} \cdot \mathrm{cm}^{-1}\right.$ and $41 \mathrm{mS} \cdot \mathrm{cm}^{-1}$ at $200^{\circ} \mathrm{C}$ for PBI+IL3-NaY_3\%wt and PBI+IL3-NaY_20\%wt, respectively). Comparing to bare NaY-PBI membranes, the attained improvement is at least two folds higher. At this point, it is worthwhile to remark that the IL intrinsic proton conductivity values (i.e. 159 $\mathrm{mS} \cdot \mathrm{cm}^{-1}$ vs. $185 \mathrm{mS} \cdot \mathrm{cm}^{-1}$ for IL2 and IL3 respectively at $150^{\circ} \mathrm{C}$ ), and the amount of encapsulated ILs are quite similar for both IL2-NaY and IL3-NaY samples. This observation could be explained by the presence of free reactive 1-H-3methylimidazolium cations (denoted as HMI) and bis(trifluoromethanesulfonyl)imide anions (denoted as TFSI) on the external surface of the zeolite crystals. Accounting from the poor water solubility of $\mathrm{IL}^{22}$, its leaching is prone to occur during the membrane solution sonication and stirring (see section 3.2.1 below). In fact, the improved diffusional properties of ionic liquids through NaY type zeolite (FAU structure) due to its pore size, orientation and connectivity are the key factors governing the efficiency of ILs encapsulation processes ${ }^{20,22}$. Both ions are capable to acid-base interactions with the $\mathrm{H}_{3} \mathrm{PO}_{4}$-PBI system and Grotthuss type mechanism via neighboring proton acceptor (12 sites) - donor (1 site) thorough the IL3 network. Therefore, the synergic combination $\mathrm{H}_{3} \mathrm{PO}_{4}+\mathrm{PBI}+\mathrm{IL} 3-\mathrm{NaY}$ leads to beneficial hydrogen bonding 
type interactions between $\mathrm{HMI}$, TFSI, $\mathrm{H}_{2} \mathrm{PO}_{4}{ }^{-}, \mathrm{HP}_{2} \mathrm{O}_{7}{ }^{-}$and protonated $\mathrm{PBI}$ for proton transport. Greenbaum et al., ${ }^{16}$ reported the role of 1-methyl-3-propylmethylimidazolium dihydrogen phosphate ionic liquid to adjust the strength of hydrogen bonding in $\mathrm{H}_{3} \mathrm{PO}_{4}+$ PBI systems for optimized proton transport. Due to strong acid-base interaction between $\mathrm{H}_{3} \mathrm{PO}_{4}$ and $\mathrm{PBI}$, the relatively weaker hydrogen bonding between 1-methyl-3-propyl-methylimidazolium dihydrogen phosphate and PBI balance this effect. A similar hypothesis could be postulated for the $\mathrm{H}_{3} \mathrm{PO}_{4}+\mathrm{PBI}+\mathrm{IL} 3-$ $\mathrm{NaY}$ system. In this work, the role of 1-methyl-3-propyl-methylimidazolium dihydrogen phosphate ionic liquid molecules is played by HMI cations and TFSI anions leached out from the FAU microporous cavities.

Therefore, the PBI+IL3-NaY_3\% wt membrane emerges as the most adequate among the tested as inferred for proton conductivity measurements up to $200^{\circ} \mathrm{C}$. Consequently, the next section is devoted to a more comprehensive characterization of the electrolyte membrane and MEA testing in $\mathrm{H}_{2} / \mathrm{O}_{2}$ single cell at temperatures up to $180{ }^{\circ} \mathrm{C}$

\subsection{Optimized IL3-NaY composite membranes: Characterization and MEA} testing

\subsubsection{Conductivity and durability}

The proton conduction for PBI+IL3-BEA_3\% wt membrane, like almost all the ILzeolite PBI samples, exhibit the same conduction pattern with temperature: a gradual increase up to a maximum, followed by a slight decay and a subsequent activation in the high temperature range (always above $120^{\circ} \mathrm{C}$ ). To get insight this behavior, an additional experience was performed onto PBI+IL3-BEA_3\% wt membrane at "steady" conditions. For such purposes, conductivity values were recorded after 2 h stabilization 
time at each temperature step. The obtained results are plotted in Figure 8, where the standard conduction experience carried out at "dynamic" conditions $\left(0.5^{\circ} \mathrm{C} / \mathrm{min}\right.$ as heating rate) has also been depicted for comparison purposes. The exhibited behavior underlines the effect of water sorption kinetics. As it was expected, the "steady" conductivity values in the low temperature region (below $90^{\circ} \mathrm{C}$ ) are lower than "dynamic" counterparts in agreement with the hygroscopic nature of membrane materials (see Table 2). In fact, the water uptake value estimated by TGA for PBI+IL3BEA_3\% wt membrane is circa 13\% wt.

The steady state conductivity measurements performed on stabilized PBI+IL3NaY_3\%wt sample show a linear relationship between the reciprocal temperature and conductivity. Nevertheless, two distinguished temperature operating regions could be ascertained in accordance with the existence of several proton pathways contributing to the conduction properties. The calculated activation energy value for the lowintermediate temperature region (below $120^{\circ} \mathrm{C}$ ) is $6.6 \mathrm{~kJ} / \mathrm{mol}$. However, it is particularly noticeable the conductivity temperature dependence above $120^{\circ} \mathrm{C}$. In fact, the calculated activation energy for the temperature region above $120^{\circ} \mathrm{C}$ is $53.7 \mathrm{~kJ} / \mathrm{mol}$. At present, we are still unable to provide strong evidence about the true ion-conduction mechanism. Our hypothesis relies on the combination of different proton pathways as a function of the operating temperature. In the low-intermediate temperature region, the proton conduction is mainly controlled by the water-vehicle mechanism through hydrophilic domains and proton hopping due to acid-base type interactions between H3PO4 and PBI backbone. As the temperature increases and water desorption is predominant, in addition to proton hopping through pyrophosphoric acid doped PBI chains, the contribution of less hygroscopic HMI cations and TFSI anions to the proton bonding 
network becomes more noticeable and clearly beneficial. The proposed proton transport mechanism is schematized in Figure 9 for both operating temperature regions.

In this scenario, the presence of ionic liquid ions could be explained by its diffusion from the internal to the external $\mathrm{NaY}$ surface through the 3-dimensional microporous network $0.74 \mathrm{~nm}$ in size during polymer solution preparation (DMAc as solvent) and membrane casting steps. To corroborate our hypothesis, ATR-FTIR analysis of undoped PBI+IL3-NaY_3\%wt membrane was compared to pristine undoped PBI and pure IL3 (see Figure 10.a). A similar study was performed over the "simulated" casting solution, that means in absence of PBI polymer and after $\mathrm{NaY}$ crystals filtration (see Figure 10.b), and compared with pure IL and DMAc solvent. The typical absorption bands at $3450-3250 \mathrm{~cm}^{-1}$ due to the stretching vibrations of $\mathrm{N}-\mathrm{H}$ groups corresponding to the HMI cations are overlapped with those characteristics of pristine PBI. On the contrary, the presence of peaks at $1200-1185 \mathrm{~cm}^{-1}$ and $1365-1315 \mathrm{~cm}^{-1}$ were attributed to $\mathrm{R}-\mathrm{SO}_{2}$ $\mathrm{N}$ stretching vibration of TFSI anions. For the simulated casting solution, the intense absorption bands at 3400-3000 $\mathrm{cm}^{-1}$ attributed to $\mathrm{N}-\mathrm{H}$ stretching mode of HMI cations are shifted to $3600-3400 \mathrm{~cm}^{-1}$ spectral region due to solvent interactions. The C-H out of plane deformation vibration mode is also reflected in the $770-710 \mathrm{~cm}^{-1}$ region. Unfortunately, the highly diluted concentration levels of IL3 in DMAc hinder the TFSI anions identification. These results corroborate our hypothesis on IL3 extraction from the internal NaY microporous surface by DMAc during hybrid membrane preparation.

For the assessment of endurance properties, extended through-plane conductivity experiments (up to $200 \mathrm{~h}$ ) have been carried out. In particular, the durability test at $150^{\circ} \mathrm{C}$ shown in Figure 11 is the prolongation of the steady state data set depicted in Figure 8 . Thus, once the membrane conductivity was evaluated at $180^{\circ} \mathrm{C}$, it was kept overnight at $150^{\circ} \mathrm{C}$. The maximum decay in performance (circa $35 \%$ ) is reached after 
60 h operation time. These conductivity losses could be mainly associated with the autodehydration of phosphoric acid. Afterwards, the conductivity remains constant at 32 $\mathrm{mS} \cdot \mathrm{cm}^{-1}$ under $\mathrm{N} 2$ flow in presence of 0.05 water molar fraction. The reported conductivity at $150^{\circ} \mathrm{C}$ is slightly higher than the evaluated with increasing temperature $(18 \mathrm{mS} \cdot \mathrm{cm}-1)$. This behavior could be associated with the activated diffusion of remaining ionic liquid ions from the internal to the external surface of the zeolite crystals, providing additional pathways for proton hopping. Thus, the incorporation of composite fillers to the PBI casting solution allows maintaining a satisfactory performance after long-term operation at $150^{\circ} \mathrm{C}$.

\subsection{2. $\mathrm{H}_{2}$ permeability and $\mathrm{H}^{+} / \mathrm{H}_{2}$ transport selectivity}

Figure 12 summarizes the $\mathrm{H}_{2}$ permeation properties for the hybrid IL-zeolite based membranes with $3 \%$ of inorganic filler once evacuated (50 mbar) at $80^{\circ} \mathrm{C}$ for at least 24 h. Pristine PBI membrane performance has also been included for comparison. In general, the so obtained values are rather similar to those previously reported in the literature for cross-linked PBI membranes applied to gas separation ${ }^{26}$. At the examined conditions, the $\mathrm{H}_{2}$ permeability values were in the following order: PBI > PBI+IL1BEA_3\%wt > PBI+IL2-BEA_3\%wt > PBI+IL2-NaY_3\%wt > PBI+IL3-NaY_3\%wt. Thus, for a given temperature, the permeability is always higher for pristine PBI, although the differences are not quite noticeable in agreement with the improved organic-inorganic interface and the barrier effect imposed by the microporous filler. Moreover, the $\mathrm{H}_{2}$ fluxes slightly decreased with temperature for all the membranes excepting the PBI+IL3-NaY_3\%wt with permeability values almost constant. It seems 
that the $\mathrm{H}_{2}$ solubility-diffusivity throught the PBI chains is controlling the permeation mechanism in the studied temperature range.

The $\mathrm{H}+/ \mathrm{H} 2$ transport selectivity of the optimum IL3-NaY composite membrane has been calculated in this work as the $\mathrm{H}+$ conductivity/H2 permeability ratio at $50{ }^{\circ} \mathrm{C}, 100$ ${ }^{\circ} \mathrm{C}$ and $150{ }^{\circ} \mathrm{C}$ in agreement with our previous works ${ }^{[14,19]}$. Such ratio is underlying the typical trade-off between the two most relevant parameters for PEMs: conductivity and fuel cross-over. To summarize, Table 3 shows the obtained values in comparison to PBI and zeolite-PBI counterparts. Similarly to reference samples, the reported selectivity values for the optimum hybrid PBI membrane increase with temperature mainly due to the activated proton conduction. As a result, the PBI+IL3-NaY_3\%wt membrane reveals as the most adequate in the full temperature range. At $150{ }^{\circ} \mathrm{C}$, the evaluated transport selectivity value is $20.2 \cdot 10^{7} \mathrm{~S} \cdot \mathrm{s} \cdot \mathrm{bar} / \mathrm{mol}$ for the optimum membrane vs. $1.78 \cdot 10^{7} \mathrm{~S} \cdot \mathrm{s} \cdot \mathrm{bar} / \mathrm{mol}$ and $5.09 \cdot 10^{7} \mathrm{~S} \cdot \mathrm{s} \cdot \mathrm{bar} / \mathrm{mol}$ for PBI and NaY-PBI respectively. Nevertheless, the improvements are more noticeable in the low-intermediate temperature range. In particular, a promising behaviour is observed at $100{ }^{\circ} \mathrm{C}$ where the reported transport selectivity value is 22 folds the evaluated for pristine PBI.

\subsubsection{MEA testing}

The I-V performance for the optimum PBI+IL3-NaY_3\%wt membrane in $\mathrm{H}_{2} / \mathrm{O}_{2}$ single cell at 1 bar back pressure, stoichiometric feed and non humidified conditions, have been depicted in Figure 13 as improvement porcentange over pristine PBI used as reference. The Tafel slopes were estimated from fitting the experimental data in the low current density region. The encountered values for MEAs based on pristine PBI samples (i.e $237,6 \mathrm{mV} / \mathrm{dec}$ at $150^{\circ} \mathrm{C}$ ), are quite similar to those found for PBI+IL3-NaY_3\%wt counterparts prepared from identical electrodes (i.e $269.3 \mathrm{mV} / \mathrm{dec}$ at $150^{\circ} \mathrm{C}$ ). 
The percentange of improvement for current density values, ranging from 20\% up to $100 \%$, are mainly observed in the I-V controlled by ohmic polarization in agreement with the enhanced conduction behavior of the optimum hybrid membrane. Thus, the "proof of concept" for the optimum hybrid electrolyte membrane could be considered as demonstrated. However, further efforts on "ad-hoc” MEA and FC assembly processes for these novel membranes are in progress.

\section{Conclusions}

The addition of 1-H-3-methylimidazolium bis(trifluoromethanesulfonyl)imide (IL3) imbibed in commercial NaY type zeolite to the PBI casting solution, in a 3\% wt., has been successfully demonstrated for HT PEMFCs applications. The exhibited conduction behaviour and $\mathrm{H}^{+} / \mathrm{H}_{2}$ transport selectivity of PBI+IL3-NaY_3\%wt membranes clearly outperforms pristine PBI and NaY-PBI counterparts. The postulated hypothesis to explain the results herein obtained is based on the presence of HMI cations and TFSI ions on the external surface of $\mathrm{NaY}$ crystals. Both ions are capable to acid-base interactions with the $\mathrm{H}_{3} \mathrm{PO}_{4}$-PBI system and Grotthuss type mechanism thorough the IL3 network. Moreover, the thermal and chemical stability of PBI+IL3-NaY_3\%wt membrane is sufficient to maintain a satisfactory performance after long-term operation (32 $\mathrm{mS} \cdot \mathrm{cm}^{-1}$ at $150^{\circ} \mathrm{C}$ ). In the high temperature range (above $120^{\circ}$ ), the contribution of HMI cations and TFSI anions to the proton bonding network becomes more noticeable and clearly beneficial for proton hopping.

MEAs prepared from PBI+IL3-NaY_3\%wt membranes and CCS have been validated in $\mathrm{H}_{2} / \mathrm{O}_{2}$ single cell from room conditions to $180{ }^{\circ} \mathrm{C}$ under non humidified conditions. By comparison to pristine PBI, the I-V improvement performance values, ranging from $20 \%$ up to $100 \%$, are mainly observed in the I-V controlled by ohmic 
polarization in agreement with the enhanced conduction behavior of the optimum hybrid membrane.

The results show that these membranes based on four components $\left(\mathrm{H}_{3} \mathrm{PO}_{4}, \mathrm{PBI}\right.$, NaY, IL3) are very promising for use in HTPEMFC. So far, there is no precedent of polybenzimidazole membranes that have been prepared with composite filler based on zeolite and ionic liquid, and that the synergy between doped PBI and compound filler strengthen the properties of hybrid membrane.

\section{Acknowledgments}

The authors would like to acknowledge financial support from DGA-FSE and EC through the FP7 funded project ZEOCELL (http://ina.unizar.es/zeocell) Grant Agreement 209481. 


\section{Table List}

Table 1. Main properties of the conducting fillers used in this work.

Table 2. Main properties of the hybrid doped PBI membranes developed in this work.

Table 3. $\mathrm{H}^{+} / \mathrm{H}_{2}$ transport selectivity values as a function of temperature for the optimum PBI+IL3-NaY membrane prepared in this work in comparison with dense PBI and bare NaY-PBI counterparts. 


\section{Figure Captions}

Figure 1. External view of: left) pure PBI; right) PBI+IL3-NaY_3\%wt membranes.

Figure 2. SEM analysis of the as prepared IL3-NaY composite membranes after phosphoric acid doping: left) PBI+LI3/NaY_3\%wt; center) PBI+ LI3/NaY_10\%wt; right) $\mathrm{PBI}+\mathrm{LI} / \mathrm{NaY} \_20 \% \mathrm{wt}$

Figure 3. Through-plane conductivity measurements for hybrid PBI membranes as a function of the BEA type filler loading after phosphoric acid doping at $80^{\circ} \mathrm{C}$.

Figure 4. Phosphoric Acid Uptake Values estimated by TGA for hybrid membranes based on conducting BEA type fillers.

Figure 5. Through-plane conductivity measurements for hybrid PBI membranes as a function of the $\mathrm{NaY}$ type filler loading after phosphoric acid doping at $80^{\circ} \mathrm{C}$.

Figure 6. Phosphoric Acid Uptake Values estimated by TGA for hybrid membranes based on conducting NaY type fillers.

Figure 7. ATR-FTIR analyses for doped IL3-NaY composite membranes as a function of the filler loading.

Figure 8. Through-plane conductivity values for the optimum PBI+IL3-NaY_3\%wt membrane under transient $\left(0.5^{\circ} \mathrm{C} / \mathrm{min}\right.$ as heating rate) and steady (after $2 \mathrm{~h}$ stabilization period) conditions.

Figure 9. Scheme of the hydrogen bonded type interactions for: a) $\mathrm{H}_{3} \mathrm{PO}_{4} / \mathrm{PBI}$ and $\mathrm{b}$ ) $\mathrm{H}_{3} \mathrm{PO}_{4} / \mathrm{PBI}+\mathrm{IL}-\mathrm{NaY} \_3 \% \mathrm{wt}$ membranes.

Figure 10. Study on IL3 extraction from $\mathrm{NaY}$ during membrane casting process by ATR-FTIR analyses on: a) undoped PBI+LI3/NaY_3\%wt membrane compared to Pristine PBI and pure IL3; b) simulated casting solution compared to DMAc solvent and pure IL3.

Figure 11. Durability test for the optimum PBI+LI3/NaY_3\%wt membrane at $150^{\circ} \mathrm{C}$ in presence of 0.05 water molar fraction.

Figure 12. $\mathrm{H}_{2}$ Permeability Properties of the hybrid doped PBI membranes with $3 \% \mathrm{wt}$ of inorganic filler. Pure doped PBI is also plotted as reference.

Figure 13. I-V curves for MEAs based on the optimum PBI+IL3-NaY_3\%wt membrane, expressed as percentage of improvement over pristine PBI behaviour (used as baseline) at $120^{\circ}, 150^{\circ}$ and $180^{\circ} \mathrm{C}$ 


\section{References}

${ }^{1}$ COM(2010) 2020 final. Brussells, 3.3.2010. Communication from the Commission. Europe 2020: A strategy for smart, sustainable and inclusive growth.

2 J.A. Asensio, E.M. Sanchez, P. Gomez-Romero, Chem. Soc. Rev.39 (8) (2010) 3210-3239.

${ }^{3}$ http://www.fuelcell.basf.com/

${ }^{4}$ http://www.fumatech.com/EN/Products/fumapem/

${ }^{5}$ S. Ying-Ling Liu. J. Membr. Sci. 332 (2009) 121-128.

${ }^{6}$ J. Lobato, P. Cañizares, M.A. Rodrigo, D. Úbeda, F.J. Pinar. J. Membr. Sci. (2011), 369 (1-2), 105-111.

7 J. Lobato, P. Cañizares, M.A. Rodrigo, D. Úbeda, F.J. Pinar. J. Power Sources (2011), 196 (20), 82658271.

8 J. Lobato, P. Cañizares, M.A. Rodrigo, D. Úbeda, F.J. Pinar. ChemSusChem (2011), 4 (10), 1489-1497.

${ }^{9}$ M.Q. Li, Z.G. Shao, K. Scott, K. J. Power Sources (2008), 183(1), 69-75.

${ }^{10}$ M. Sadeghi, M.A. Semsarzadeh, H. Moadel. J. Membr. Sci. 331 (2009), 21-30.

${ }^{11}$ H. Namazi, H. Ahmadi. J. Power Sources (2011), 196(5), 2573-2583.

${ }^{12}$ R. Kannan, O.P. Aher, T. Palaniselvam, S. Kurungot, U.K. Kharul, V.K. Pillai. J. Phys. Chem. Lett., (2010), 1(14), 2109-2113.

${ }^{13}$ R. Kannan, H.N. Kagalwala, H.D. Chaudhari, U.K. Kharul, S. Kurungot, V.K. Pillai. J. Mater. Chem. (2011), 21(20), 7223-7231.

${ }^{14}$ A. Eguizábal, J. Lemus, M. Urbiztondo, O. Garrido, J. Soler, J.A. Blazquez, M.P. Pina. J. Power Sources (2011), 196 (21), 8994-9007.

${ }^{15}$ T.L. Greaves, C.J. Drummond. Chem. Rev. (2008), 108, 206-237.

${ }^{16}$ H. Ye, J. Huang, J.J. Xu, N.K.A.C. Kodiweera, J.R.P. Jayakody, S.G. Greenbaum. J. Power Sources (2008), $178,651-660$.

${ }^{17}$ J. Schauer, A. Sikora, M. Plísková, J. Malis, P. Mazúr, M. Paidar, K. Bouzek, K. J. Membr. Sci. (2011), 367, 332-339.

${ }^{18}$ J.T.-W. Wang, S.L.-C. Hsu. Electrochim. Acta (2011), 56(7), 2842-2846.

${ }^{19}$ A. Eguizábal, J. Lemus, V. Roda, M. Urbiztondo, F. Barreras, M.P. Pina. Int. J. Hydrogen Energy (2012), 37 (8), 7221-7234.

${ }^{20}$ A. Eguizábal, J. Lemus, M. Urbiztondo, A.M. Moschovi, S. Ntais, V. Nikolakis, J. Soler, M.P. Pina. J. Power Sources (2011), 196 (9), 4314-4323.

${ }^{21}$ http://www.solvionic.com

${ }^{22}$ S. Ntais, A.M. Moschovi, F. Paloukis, S. Neophytides, V.N. Burganos, V. Dracopoulos, V. Nikolakis. J. Power Sources (2011), 196(4), 2202-2210.

${ }^{23}$ J. Lobato, P. Cañizares, M.A. Rodrigo, J.J. Linares, G. Manjavacas. J. Membr. Sci. (2006), 280(1-2), 351362.

${ }^{24}$ A. Lozano, L. Valiño, F. Barreras, R. Mustata. J. Power Sources (2008), 179(2), 711-722.

${ }^{25}$ A.M. López, F. Barreras, A. Lozano, J.A. García, L. Valiño, R. Mustata. J. Power Sources (2009), 192, $94-$ 99.

${ }^{26}$ B.S. Jorgensen, J.S. Young, B.F. Espinoza. US Patent 6946015. 